\title{
The Instruments of H.E. Dall
}

\author{
E.J. Hysom \\ 8 East Drive, Caldecote, Cambridge CB3 7NZ, U.K.
}

Author's note: Due to lack of space, biographical details have been largely omitted - these can be found elsewhere $(1,2,3)$. It should be noted that Horace Dall spent most of his working life as an experimental physicist with George Kent Ltd, fluidflow meter manufacturers; he was well-known for his skill in developing prototype instrumentation.

\section{Optics}

In 1926 Horace Dall commenced optical work, with interests covering both microscopes and telescopes. Soon (1928), he was making solid eyepieces of the Tolles type. Eventually he developed skills in making lenses of the smallest size to be incorporated into microscope objectives of the highest numerical aperture; this culminated in an objective with a N.A. of 1.92 (a record). The lenses were jewelled elements worked with diamond dust. During World War 2 he repaired all the microscope lenses damaged in the U.K. that had originated with the German firm of Leitz.

Horace Dall had an exceptionally inventive mind - and was so active in developing his ideas that he had insufficient time to formally write them up, hence much of his work remains unpublished. He did, however, keep extensive notebooks of his researches into optics. These, along with many prototypes, are now in the custody of the Science Museum, London. Combining his interests in travel, optics, and astronomy, Dall developed a number of portable, ultra-lightweight telescopes. He discovered that by incorporating what is in effect a long working distance, low-power microscope with a Cassegrain telescope he had an instrument with several advantages. The image was erect, the secondary small, and by use of a suitably placed internal stop, sky-flooding was eliminated without the use of shade tubes. Always looking for improvements in optical performance he hit on the idea of modifying the classical Cassegrain telescope by emplpying a prolate ellipsoidal primary mirror with a spherical secondary: independently discovered by Kirkham in the U.S.A. the type is now universally known as the Dall-Kirkham.

As an experimental physicist Dall was a great advocate of null tests - his null test for paraboloids must have resulted in tens of thousands of higher quality mirrors being made than would otherwise have been the case - this test was later extended 
to cover prolate ellipsoid and hyperbolic concave mirrors, making it immensely valuable to the optical worker. Later he developed several null tests for hyperbolic Cassegrain secondaries.

Because of his deep knowledge of optics - most of it self-taught - Dall was often used as a consultant by professional telescope makers; additionally he helped many thousands of amateurs with advice or with testing, repairing or re-figuring their optics. Finally mention must be made of some of his other achievements his early use (1939) of thin-edged primary mirrors; his micro-writing, of letters one wavelength of light high using a single diamond point on glass; of his development of the world's most accurate mechanical spherometer - it could detect 1/20th wavelength variations directly. He also developed an $\mathrm{H}-\alpha$ telescope - the Promscope that has found favour with solar observers. Now that the world of instrumentation is moving in different directions it is unlikely that the world will see his like again.

\section{References}

1. Sky \& Telescope, 72, (Oct. 1986), 410-411

2. J. Brit. astron. Assac., 97 (2), 76-80, (1987)

3. Telescope Making, 28, 4-9 